\title{
Overexpression of miR-375 reverses the effects of dexamethasone on the viability, migration, invasion and apoptosis of human airway epithelial cells by targeting DUSP6
}

\author{
XIAOJING ZHENG ${ }^{1}$, CHUNLIAN $\mathrm{LI}^{1}$ and XIANG GAO ${ }^{2}$ \\ ${ }^{1}$ Department of Pediatrics, Affiliated Hospital of Weifang Medical University, Weifang, Shandong 261031; \\ ${ }^{2}$ Department of Cardiology, Fangzi District People's Hospital, Weifang, Shandong 261206, P.R. China
}

Received May 28, 2020; Accepted November 3, 2021

DOI: $10.3892 / \mathrm{ijmm} .2022 .5081$

\begin{abstract}
Airway epithelial cell (AEC) dysfunction has been proven to be involved in the pathogenesis of asthma, which may be induced by the use of dexamethasone (Dex). The altered expression of microRNAs (miRNAs/miRs) has been found in asthma. However, the detailed mechanisms responsible for the effects of miR-375 on Dex-induced AEC dysfunction remain elusive. Thus, the present study aimed to elucidate these mechanisms. Following treatment with Dex for $0,6,12$ and $24 \mathrm{~h}, \mathrm{AEC}$ viability, migration, invasion and apoptosis were examined using Cell Counting Kit-8 (CCK-8), wound healing and Transwell assays, and flow cytometry, respectively. The expression levels of miR-375, dual specificity phosphatase 6 (DUSP6) and apoptosis-related proteins (Bcl-2, Bax, cleaved caspase-3) were measured using reverse transcription-quantitative polymerase chain reaction and western blot analysis. The target genes and potential binding sites of miR-375 and DUSP6 were predicted using TargetScan and confirmed using dual-luciferase reporter assay. The viability, migration, invasion and apoptosis of Dex-treated AECs were further assessed with or without miR-375 and DUSP6. In the AECs (9HTE cells), Dex treatment suppressed cell viability and miR-375 expression, whereas it promoted cell apoptosis and the expression of DUSP6, the target gene of miR-375. The overexpression of miR-375 reversed the effects of Dex treatment on miR-375 expression, cell viability, migration and invasion, and apoptosis-related protein expression; in turn, these effects were reversed by the overexpression of DUSP6, with the exception of miR-375 expression. On the whole, the present study demonstrates that the overexpression of miR-375 counteracts the effects of Dex treatment on AEC viability,
\end{abstract}

Correspondence to: Dr Xiaojing Zheng, Department of Pediatrics, Affiliated Hospital of Weifang Medical University, 2428 Yuhe Road, Kuiwen, Weifang, Shandong 261031, P.R. China

E-mail: zhengxiaojing_xzhe@163.com

Key words: microRNA-375, dexamethasone, metastasis, apoptosis, dual specificity phosphatase 6 migration, invasion and apoptosis by targeting DUSP6. Thus, it was suggested that the downregulated expression of miR-375 may be a therapeutic target for AEC dysfunction.

\section{Introduction}

Asthma, characterized by inflammation, the shedding of airway epithelial cells (AECs) and airway remodeling, has become one of the most prevalent chronic inflammatory airway disorders. It promotes the contractility of surrounding smooth muscles and aggravates pulmonary function, posing global economic and social burdens $(1,2)$. AECs can function as progenitors for ciliated and goblet columnar cells in major airways, accounting for $\sim 30 \%$ of the epithelium $(3,4)$. The airway epithelium can normally function as the frontline defense against respiratory viruses through the mucociliary apparatus and its immunological functions (5). It has also been found that barrier damage and the dysfunction of AECs may be related to the onset of asthma (6). Consequently, the therapeutic methods used for the prevention of the damage and dysfunction of AECs may be employed for the treatment of asthma.

Inhaled glucocorticoids (GCs), also termed inhaled corticosteroids (ICS), have been widely applied in the treatment and prevention of asthma, with anti-allergy, anti-inflammatory and immunosuppressive properties (7), which mainly function by exerting suppressive effects on inflammation in the airways (8). However, GCs were also considered to possibly adversely affect the repair process during which the proliferation and migration of AECs are suppressed (9). At present, the underlying molecular mechanisms of GCs in these processes remain unclear. Therefore, further insight into the mechanisms of GCs may be conducive to providing novel genetic strategies for the treatment of asthma.

The altered expression levels of microRNAs (miRNAs/miRs) have also been found to be involved in the development of asthma (10). Zhang et al (11) proposed that miR-221 was involved in AEC injury in asthma by targeting sirtuin 1 (SIRT1), whilst Zhou et al (12) indicated that miR-155 could function as a novel target in allergic asthma. In addition, miR-29c has been found to play a vital role in children with asthma by regulating Th2/Th17 cell differentiation (13). Lu et al (14) indicated that 
miR-375 was predominately expressed in esophageal and bronchial epithelial cells, and the upregulation of miR-375 was sufficient to modify interleukin 13-associated immunoinflammatory pathways in epithelial cells. However, the mechanisms of miR-375 as regards the amelioration of GC-induced AEC dysfunction warrant further investigation.

Dual specificity phosphatases (DUSPs) are considered to be major modulators of signaling pathways affecting various physiological processes (15). DUSP6, as a member of the DUSPs, is a cytoplasmic enzyme, which is perceived as a key cytoplasmic anchor of extracellular signal-regulated kinases (ERKs) and a regulator of the ERK signaling cascade (15). Previous studies have suggested that DUSP6 is involved in the progression of multiple diseases, such as cancer, inflammation-related diseases and chronic obstructive pulmonary disease (16-18). Recent evidence has suggested that long non-coding RNA taurine-upregulated gene 1 promotes airway remodeling by inhibiting the miR-145-5p/DUSP6 axis in smoking-induced chronic obstructive pulmonary disease (18). Of note, DUSP6 is a known oncogene regulating cellular differentiation and proliferation in thyroid cancer, whose expression is inferred to correlate with that of miR-375 (19). Therefore, it was hypothesized that miR-375 may modulate AEC dysfunction by regulating DUSP6 expression.

The present study mainly focused on the role and function of miR-375 in ameliorating dexamethasone (Dex)-induced AEC dysfunction, with the aim of assisting in the development of a possible treatment for AEC dysfunction.

\section{Materials and methods}

Cells, cell culture and reagents. Human AECs (the 9HTE cell line), were obtained from the Respiratory Research Laboratory (Key Laboratory of Child Development and Disorders of Ministry of Education, Children's Hospital, Chongqing, China). The cells were grown in Dulbecco's modified Eagle's medium (DMEM; 01-057-1A, Biological Industries) supplemented with $10 \%$ fetal bovine serum (FBS; 04-001-1A, Biological Industries) at $37^{\circ} \mathrm{C}$ with $5 \% \mathrm{CO}_{2}$.

Dex (D1756) was purchased from Sigma-Aldrich; Merck KGaA. The 9HTE cells were divided into four groups as follows: i) The control group, cells were incubated in DMEM without Dex treatment; ii) Dex 6 group, cells were incubated in DMEM and then treated with $10 \mu \mathrm{mol} / \mathrm{l}$ Dex for $6 \mathrm{~h}$; iii) Dex 12 group, cells were incubated in DMEM and then treated with $10 \mu \mathrm{mol} / 1$ Dex for $12 \mathrm{~h}$; and iv) Dex 24 group, cells were incubated in DMEM and then treated with $10 \mu \mathrm{mol} / \mathrm{l}$ Dex for $24 \mathrm{~h}$.

It was found that $10 \mu \mathrm{mol} / 1$ Dex treatment exerted the optimal effects on the AECs after $24 \mathrm{~h}$. Subsequently, to determine the effects of Dex treatment, miR-375 and DUSP6 on 9HTE cells, the cells were transfected with miR-375 mimic (M) and its control (MC), as well as with overexpression DUSP6 plasmid and its negative control (NC), followed by treatment with or without $10 \mu \mathrm{mol} / 1 \mathrm{Dex}$ for $24 \mathrm{~h}$. The transfection protocol is described below.

Cell Counting Kit-8 (CCK-8) assay. The transfected 9HTE cells $\left(1 \times 10^{4}\right.$ cells/well $)$ were seeded into a 96 -well plate in DMEM containing $10 \% \mathrm{FBS}$ at $37^{\circ} \mathrm{C}$ with $5 \% \mathrm{CO}_{2}$.
Subsequently, $10 \mu 1$ CCK-8 reagent (GK10001; GLPBio) with serum-free DMEM was then added into each well to detect cell viability at 12 and $24 \mathrm{~h}$. The absorbance at $450 \mathrm{~nm}$ was measured using an iMark ${ }^{\mathrm{TM}}$ Microplate Absorbance Reader (168-1020; Bio-Rad Laboratories, Inc.).

Flow cytometry. 9HTE cell apoptosis was detected using flow cytometry with an Annexin V-FITC/propidium iodide (PI) apoptosis kit (A211; GeneBio Systems, Inc.) as per the manufacturer's instructions. Following transfection for $48 \mathrm{~h}$, the 9HTE cells were harvested and then washed with cold phosphate-buffered saline (PBS) twice, followed by treatment with both Annexin V and PI (5 $\mu 1 /$ well) for $20 \mathrm{~min}$ in the dark at room temperature. Cell apoptosis was further analyzed using a Guava easyCyte Benchtop Flow Cytometer (BR168323; Luminex Corporation) and Kaluza C Analysis Software (version 1.1.1, Beckman Coulter, Inc.).

$R N A$ isolation and reverse transcription-quantitative polymerase chain reaction ( $R T-q P C R)$. Total RNA was extracted from the 9HTE cells using TRIzol $^{\circledR}$ reagent $(15596026$; Invitrogen; Thermo Fisher Scientific, Inc.) and cryopreserved at $-80^{\circ} \mathrm{C}$. The concentration of total RNA was quantified using a NanoDrop Lite UV-Vis spectrometer (ND-LITE, Thermo Fisher Scientific, Inc.). cDNA was synthesized from $1 \mu \mathrm{g}$ of total RNA with an Optimax First strand cDNA Synthesis kit (K4201100, BioChain Institute, Inc.). In detail, the reaction components were mixed, and the mixture was incubated at $42^{\circ} \mathrm{C}$ for $60 \mathrm{~min}$; the reaction was then terminated by incubating the tube at $70^{\circ} \mathrm{C}$ for $10 \mathrm{~min}$. The qPCR experiment was conducted using a QCell-Pro One-Step qRT-PCR SuperMix kit (K5055400, BioChain Institute, Inc.) on a Touch real-time PCR Detection system (CFX384, Bio-Rad Laboratories, Inc.) under the following conditions: $95^{\circ} \mathrm{C}$ for $10 \mathrm{~min}$, followed by 40 cycles of $95^{\circ} \mathrm{C}$ for $15 \mathrm{sec}$ and $60^{\circ} \mathrm{C}$ for $1 \mathrm{~min}$. The primer sequences are presented in Table I. $\beta$-actin and U6 were used as internal controls. The expression levels of relative genes were quantified using the $2^{-\Delta \Delta \mathrm{Cq}}$ calculation method (20).

Cell transfection. miR-375 mimic (B02003, sequence: 5'-UUUGUUCGUUCGGCUCGCGUGA-3') and its control (B04001, sequence: 5'-UUGCCAUUUGGUAUGUGCGG UU-3') were purchased from Shanghai GenePharma Co., Ltd. The DUSP6 overexpression sequence was structured by Thermo Fisher Scientific, Inc. and inserted into the PcDNA3.1 plasmid (V79020; Thermo Fisher Scientific, Inc.) for preparing the DUSP6 overexpression plasmid, and empty PcDNA3.1 plasmid was used as a negative control. The 9HTE cells were then cultured in a 96-well plate at a density of $2 \times 10^{4}$ cells/well until reaching $80 \%$ confluence, and $0.2 \mu \mathrm{g}$ mimic and its control, as well as $50 \mathrm{nmol}$ DUSP6 overexpression plasmid were transfected into the cells using Lipofectamine ${ }^{\circledR} 3000$ reagent (L3000-001; Thermo Fisher Scientific, Inc.) at $37^{\circ} \mathrm{C}$. The cells were harvested at $48 \mathrm{~h}$ post-transfection and were then treated with $10 \mu \mathrm{mol} / 1 \mathrm{Dex}$ for $24 \mathrm{~h}$. The expression levels of miR-375 and DUSP6 in the treated cells were measured using RT-qPCR or western blot analysis.

Wound healing assay. At $48 \mathrm{~h}$ post-transfection, the 9HTE cells $\left(1 \times 10^{5}\right.$ cells/well $)$ were cultured in a 24 -well plate. 
Table I. Sequences of primers used for reverse transcription-quantitative PCR in the present study.

\begin{tabular}{lll}
\hline Gene ID & \multicolumn{1}{c}{ Forward sequence (5'-3') } & \multicolumn{1}{c}{ Reverse sequence $\left(5^{\prime}-3^{\prime}\right)$} \\
\hline miR-375 & CTCGCGTGAGTCGTATCCAG & GTATCCAGTGCGTGTCGTGG \\
miR-let-7 & CAGCACTGAGGTAGTAGGTT & CTGAGGCTCACTGACACAA \\
miR-21 & GTGCAGGGTCCGAGGT & GCCGCTAGCTTATCAGACTGATGT \\
miR-19 & TGTGCAAATCTATGCAAA & GTGCAGGGTCCGAGGTATTC \\
miR-455 & ACACTCCAGCTGGGGCAGTCCATGGGCAT & TGGTGTCGTGGAGTCG \\
DUSP6 & GCTATACGAGTCGTCGCACA & CGGGCTTCATCTTCCAGGTA \\
U6 & CTCGCTTCGGCAGCACATATACT & ACGCTTCACGAATTTGCGTGTC \\
$\beta$-actin & ATTGGCAATGAGCGGTTC & GGATGCCACAGGACTCCA
\end{tabular}

miR, microRNA; DUSP6, dual specificity phosphatase 6.

After the cells reached $80 \%$ confluency, a scratch was created in the middle of each well using a sterile pipette tip. The cells were then washed twice with PBS to smooth the scratch edge and remove floating cells. Subsequently, the cells were cultured in serum-free DMEM at $37^{\circ} \mathrm{C}$ with $5 \% \mathrm{CO}_{2}$. Cell images at 0 and $24 \mathrm{~h}$ were captured under an automated fluorescence microscope (BX63; Olympus Corporation). Cell migration was detected at x100 magnification and quantified using Image-Pro Plus Analysis software 7.0 (Media Cybernetics, Inc.).

Transwell invasion assay. Transwell chambers (8- $\mu \mathrm{m}$-pore size; CLS3422, Sigma-Aldrich; Merck KGaA) were placed in a 24-well plate, the upper chamber of which was coated with $50 \mu$ l Matrigel (356235, Corning, Inc.). The transfected 9HTE cells were subsequently transferred onto the upper chamber at $37^{\circ} \mathrm{C}$ with $5 \% \mathrm{CO}_{2}$, and $500 \mu \mathrm{l}$ DMEM containing $10 \% \mathrm{FBS}$ were added to the lower chamber as a chemoattractant. After $24 \mathrm{~h}$, the lower chamber was washed multiple times with PBS, and the unmigrated cells in the upper chamber were gently removed using cotton swabs. The lower Transwell chamber was first fixed in $4 \%$ paraformaldehyde solution for $30 \mathrm{~min}$ and subsequently stained with $0.1 \%$ hematoxylin (H3136, Sigma-Aldrich; Merck KGaA) for $20 \mathrm{~min}$ at room temperature. The number of cells in five randomly selected fields was counted under an inverted optical microscope (DP27, Olympus Corporation) and photographed at x100 magnification.

Target gene prediction and dual-luciferase reporter assay. The target gene and potential binding sites between miR-375 and DUSP6 were predicted using TargetScan (http://www. targetscan.org/vert_72/) and confirmed using dual-luciferase reporter assay.

Subsequently, a luciferase reporter with their 3'-untranslated regions (3'-UTRs) was constructed. PMIR-REPORT Luciferase reporter (AM5795; Thermo Fisher Scientific, Inc.) containing the wild-type (WT) or mutated (MUT) DUSP6 sequence was cloned into the pMirGLO reporter vector (E1330; Promega Corporation) to form DUSP6-WT (sequence, 5'-CCACUU CUUAAAACAGAACAAA-3') and DUSP6-MUT (sequence, 5'-CCACUUCUUAAAACAACC AGUC-3'). The 9HTE cells were cultured in a 24-well plate at a density of $3 \times 10^{4}$ cells/well and co-transfected or not with DUSP6-WT (500 ng/well) and DUSP6-MUT (500 ng/well) with $500 \mathrm{ng}$ of miR-375 mimic (M; B02003; Gene Pharma, China) using Lipofectamine ${ }^{\circledR} 3000$ reagent at $37^{\circ} \mathrm{C}$. After $48 \mathrm{~h}$, the Firefly luciferase activity was detected and normalized to Renilla luciferase activity using the dual-luciferase reporter assay system (E1910; Promega Corporation).

Western blot analysis. The protein expression levels of related genes were measured by western blot analysis as previously described (3). After collecting the transfected cells, proteins were lysed and extracted using RIPA buffer (RIPA-50; FIVEphoton Biochemicals. The protein concentration was measured using a Bicinchoninic Acid (BCA) Protein kit (SK3021, Bio Basic Inc.). Sample protein lysates were electrophoresed by sodium dodecyl sulfate-polyacrylamide gel electrophoresis (SDS-PAGE; 12\% gel; P0012A; Beyotime Institute of Biotechnology), and then transferred onto a polyvinylidene fluoride (PVDF) membrane (FFP28; Beyotime Institute of Biotechnology). After blocking with 5\% non-fat milk for $2 \mathrm{~h}$ at room temperature, the membrane was incubated with primary antibodies including anti-Bcl-2 antibody (rabbit, 1:1,000, cat. no. ab59348), anti-Bax antibody (rabbit, 1:10,000, cat. no. ab32503), anti-cleaved caspase-3 antibody (rabbit, cat. no. ab2302, 1:1,000), anti-DUSP6 antibody (goat, $1: 450$, cat. no. ab166922) and anti- $\beta$-actin antibody (mouse, 1:1,000, cat. no. ab8226) (all from Abcam) at $4^{\circ} \mathrm{C}$ overnight. $\beta$-actin was used as an internal reference. The membrane was then incubated with the secondary horseradish peroxidase (HRP)-conjugated antibodies, including goat anti-rabbit IgG H\&L (HRP; 1:10,000, cat. no. 65-6120), goat anti-mouse IgG H\&L (HRP; 1:10,000, cat. no. 62-6520) (both from Thermo Fisher Scientific, Inc.) and donkey anti-goat IgG H\&L (HRP; 1:20,000, cat. no. ab6885, Abcam) at room temperature for $1 \mathrm{~h}$ and washed with tris-buffered saline Tween-20 (TBST) three times. Protein bands were collected from the samples and analyzed using an Enhanced Chemiluminescence (ECL) kit (PCD-250, FIVEphoton Biochemicals). Gray values of the bands were further analyzed and calculated using ImageJ 5.0 software (Bio-Rad Laboratories, Inc.).

Statistical analysis. All experiments were conducted in triplicate independently. Data are expressed as the mean \pm standard 

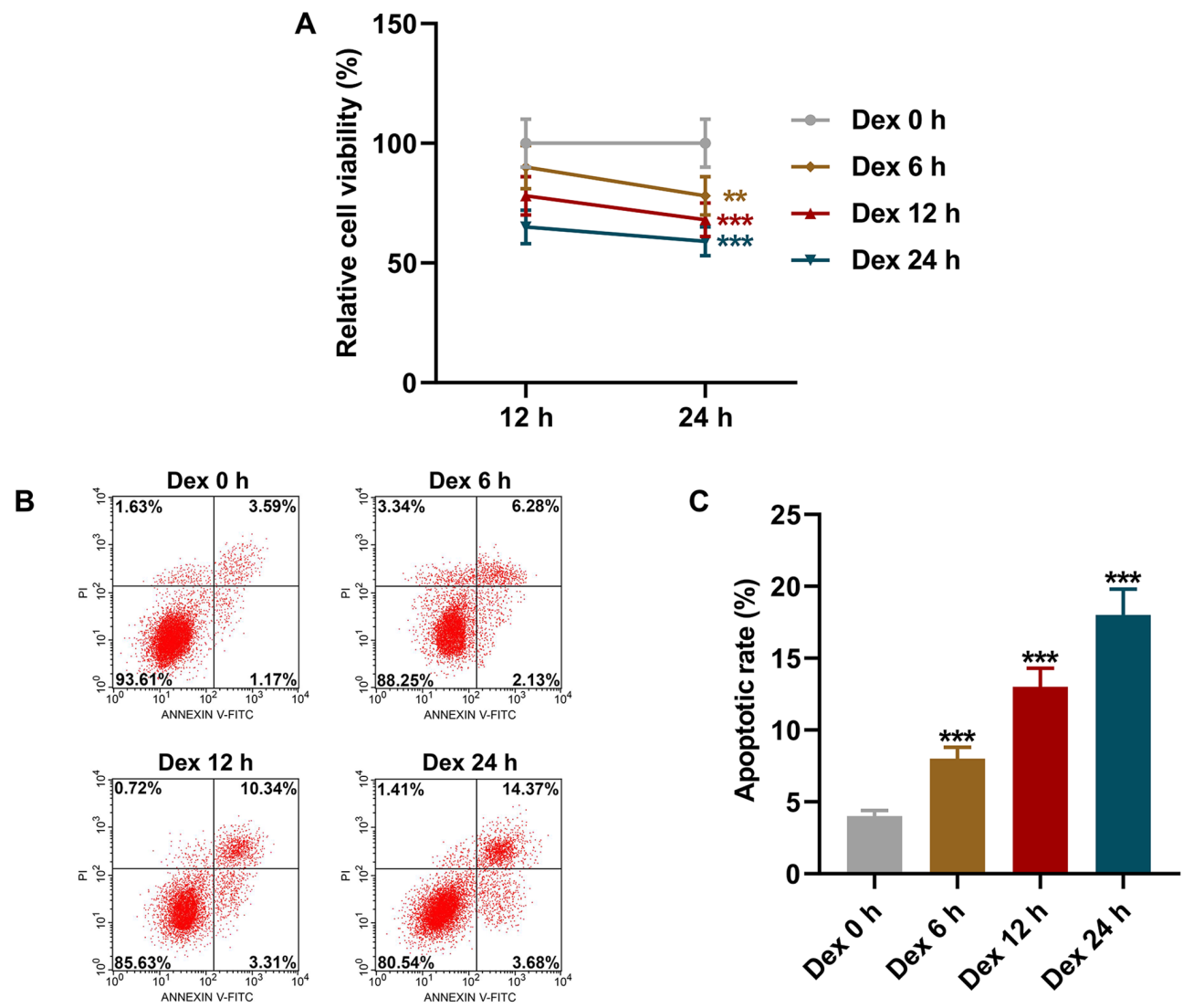

D

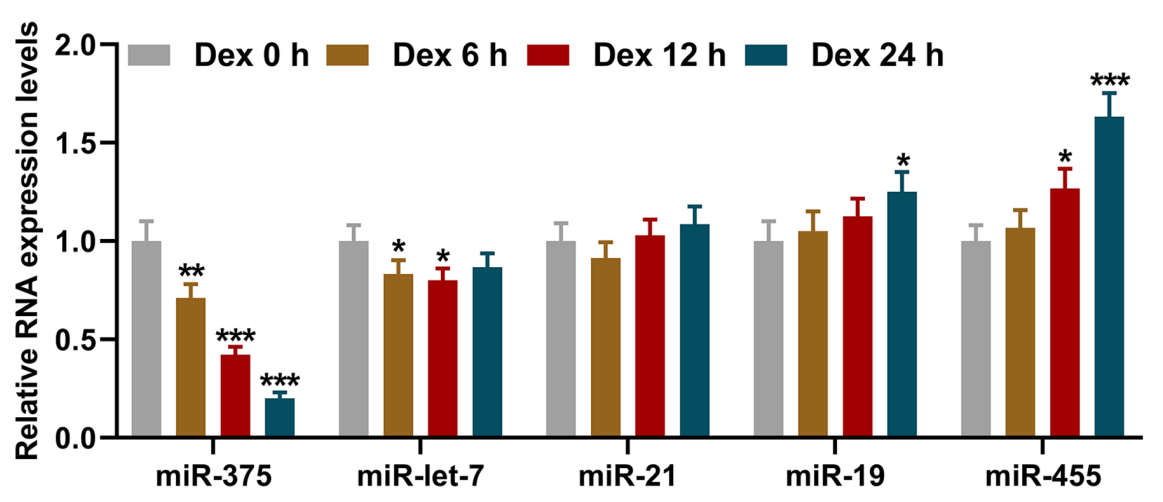

Figure 1. Dex treatment suppressed miR-375 expression and the viability of 9HTE cells, and promoted apoptosis in a time-dependent manner. (A) Cell viability following Dex pre-treatment for different periods of time ( $0,6,12$ and $24 \mathrm{~h}$ ) followed by incubation for a further 12 or $24 \mathrm{~h}$ detected using Cell Counting Kit- 8 assay. (B and C) Cell apoptotic rate following Dex treatment for different periods of time $(0,6,12$ and $24 \mathrm{~h}$ ) detected using flow cytometry. (D) Relative expression levels of miR-375, miR-let-7, miR-21, miR-19 and miR-455 in cells following Dex treatment for different periods of time $(0,6,12$ and $24 \mathrm{~h})$ measured using reverse transcription-quantitative PCR. U6 was employed as an internal control. All experiments were performed in triplicate and experimental data are expressed as the mean \pm standard deviation. ${ }^{*} \mathrm{P}<0.05,{ }^{* *} \mathrm{P}<0.01$ and ${ }^{* * * *} \mathrm{P}<0.001$ vs. Dex 0 h. Dex, dexamethasone.

deviation (SD). Statistical analysis was performed using SPSS 17.0 software (IBM Corp). Statistical significance was determined using one-way analysis of variance (ANOVA) followed by Tukey's post hoc test. $\mathrm{P}<0.05$ was considered to indicate a statistically significant difference.

\section{Results}

Dex treatment suppresses miR-375 expression and the viability of $9 H T E$ cells, and promotes apoptosis in a time-dependent manner. The 9HTE cells were pre-treated with Dex for 0,6 , 12 and $24 \mathrm{~h}$ and then incubated for a further 12 or $24 \mathrm{~h}$ to examine the effects of Dex treatment on cell viability and apoptosis, and the expression of miR-375. The results revealed that 9HTE cell viability was decreased in a time-dependent manner $(\mathrm{P}<0.01$, Fig. $1 \mathrm{~A})$, suggesting that Dex treatment suppressed 9HTE cell viability.

The effects of Dex treatment for different periods of time $(0,6,12$ and $24 \mathrm{~h})$ on 9HTE cell apoptosis were subsequently detected using flow cytometry. As shown in Fig. 1B and C, the apoptotic rate of the 9HTE cells increased in a time-dependent manner following treatment with Dex $(\mathrm{P}<0.001$, Fig. 1B and 1C), which indicated that Dex treatment promoted 9HTE cell apoptosis.

Previous studies have reported that differentially expressed miRNAs are involved in the progression of asthma, such as 
A

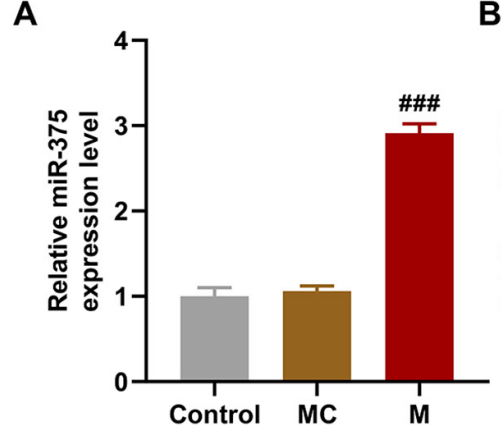

B

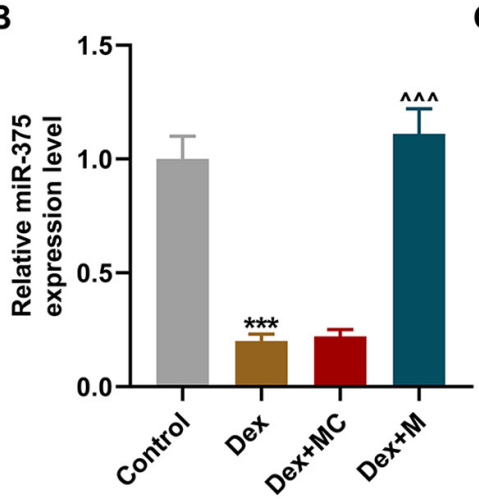

C

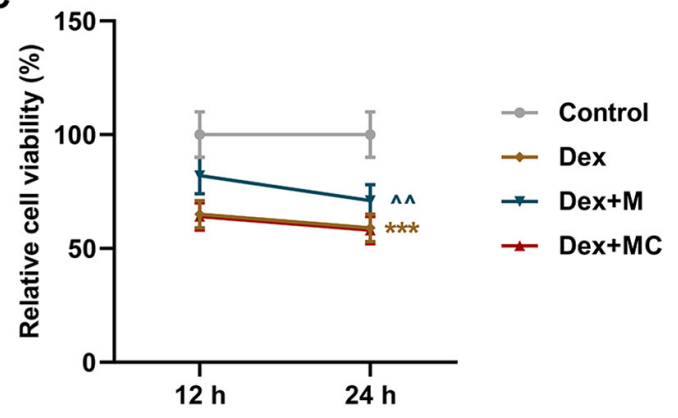

D
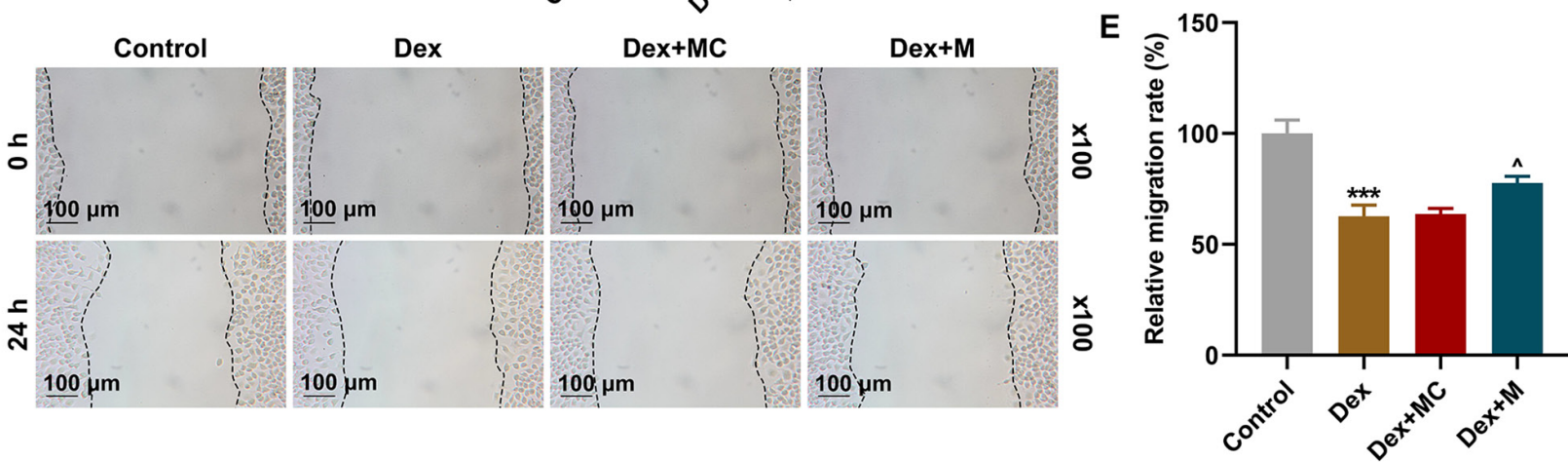

F

G

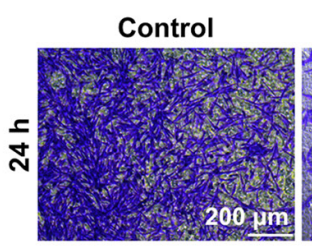
Dex Dex+MC
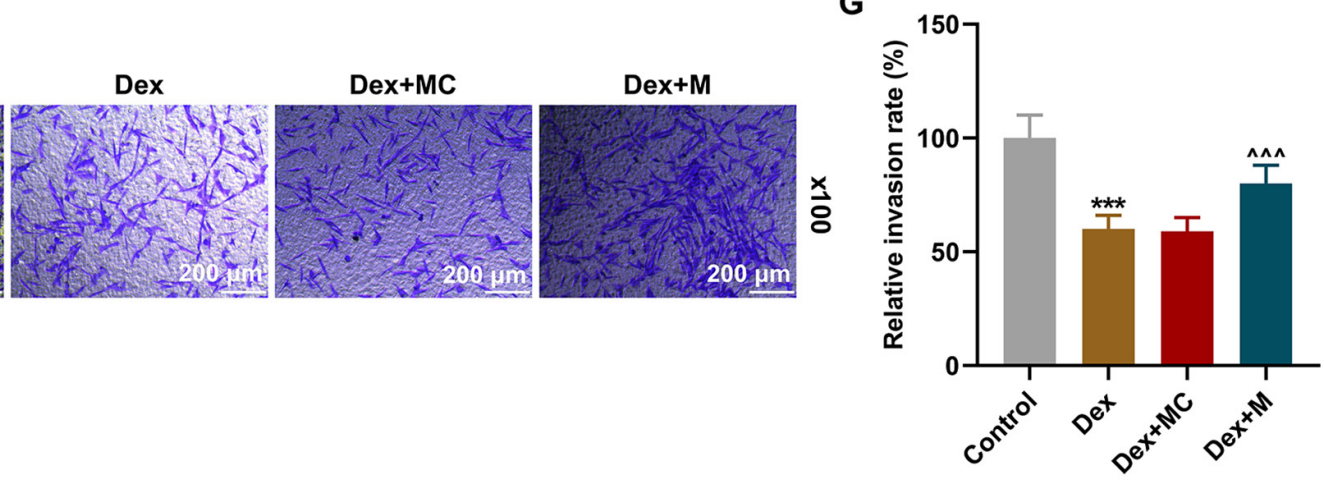

Figure 2. Overexpression of miR-375 reverses the effects of Dex treatment on miR-375 expression, cell viability, migration and invasion of 9HTE cells. (A) Relative miR-375 expression following transfection with miR-375 mimic measured using RT-qPCR. U6 was employed as an internal control (B) Relative miR-375 expression following Dex treatment and transfection with miR-375 mimic measured using RT-qPCR. U6 was employed as an internal control (C) Cell viability following Dex treatment and transfection with miR-375 mimic detected using Cell Counting Kit-8 assay at 12 and $24 \mathrm{~h}$. (D and E) Relative cell migration rate following Dex treatment and transfection with miR-375 mimic measured using wound healing assay at 0 and $24 \mathrm{~h}$ at $\mathrm{x} 100 \mathrm{magnification}$ (F and G) Relative cell invasion rate following Dex treatment and miR-375 mimic transfection measured using Transwell assay at $24 \mathrm{~h}$ at $\mathrm{x} 100 \mathrm{magnification}$. All experiments were performed in triplicate and experimental data are expressed as the mean \pm standard deviation. ${ }^{\# \# \#} \mathrm{P}<0.001 \mathrm{vs}$. MC; ${ }^{* * * *} \mathrm{P}<0.001 \mathrm{vs}$. control; ${ }^{\wedge} \mathrm{P}<0.05,{ }^{\wedge} \mathrm{P}<0.01,{ }^{\wedge \wedge} \mathrm{P}<0.001$ vs. Dex + MC. MC, miR-375 mimic control; M, miR-375 mimic; Dex, dexamethasone; RT-qPCR, reverse transcription-quantitative PCR.

miR-375, miR-let-7, miR-21, miR-19 and miR-455 (21,22). Subsequently, the effects of Dex treatment for different periods of time $(0,6,12$ and $24 \mathrm{~h})$ on the expression levels of miR-375, miR-let-7, miR-21, miR-19 and miR-455 in the 9HTE cells were determined using RT-qPCR. It was found that the expression of miR-375 in the 9HTE cells was downregulated following treatment with Dex for different periods of time $(\mathrm{P}<0.01$, Fig. 1D), suggesting that Dex treatment downregulated the expression of miR-375 in 9HTE cells.

Overexpression of miR-375 reverses the effects of Dex treatment on the expression of miR-375, and on the viability, migration and invasion of $9 H T E$ cells. Dex treatment for $24 \mathrm{~h}$ was proven to exert optimal effects on the AECs. Thus, the present study then transfected the 9HTE cells with miR-375 mimic control or miR-375 mimic. It was found that the level of miR-375 was increased by transfection with miR-375 mimic $(\mathrm{P}<0.001$, Fig. 2A). Subsequently, to further investigate the association between miR-375 and Dex treatment, the 9HTE cells were treated with Dex with or without transfection with miR-375 mimic control or miR-375 mimic. As depicted in Fig. 2B, the expression of miR-375 was notably downregulated following Dex treatment, whereas the overexpression of miR-375 reversed the effects of Dex treatment ( $\mathrm{P}<0.001$, Fig. 2B).

The viability of the 9HTE cells was assessed using CCK-8 assay following Dex treatment and transfection with miR-375 mimic. It was noted that following treatment with Dex for $24 \mathrm{~h}, 9$ HTE cell viability was decreased, whereas the overexpression of miR-375 reversed the effects of Dex treatment on 9HTE cell viability $(\mathrm{P}<0.01$, Fig. $2 \mathrm{C})$. 

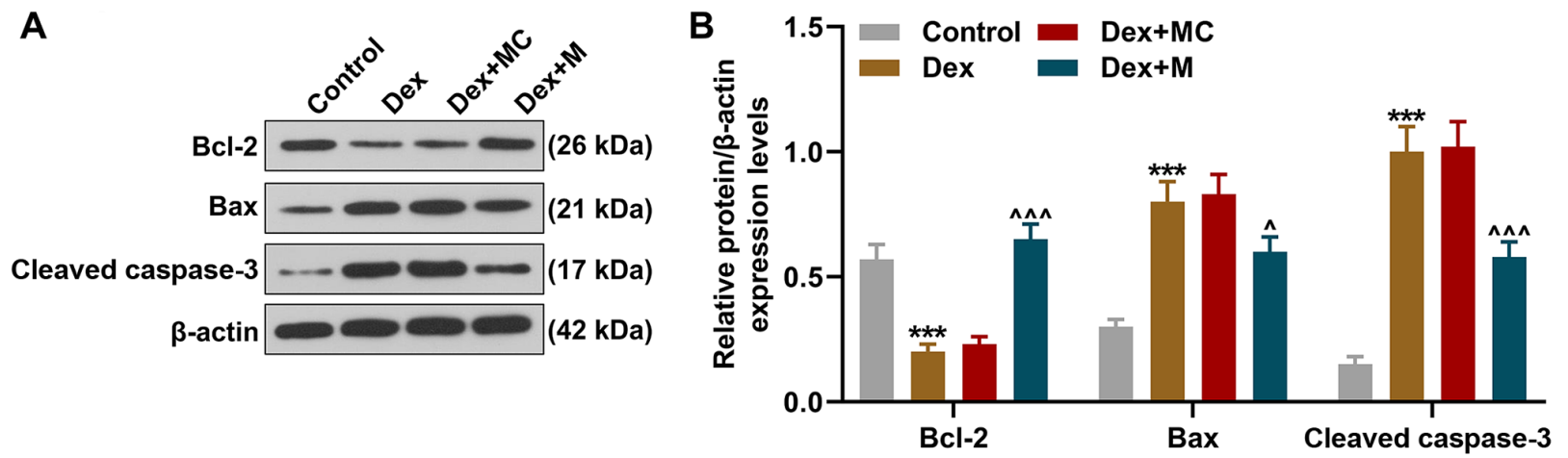

Figure 3. Overexpression of miR-375 reverses the effects of Dex treatment on the expression levels of apoptosis-related proteins. (A and B) Protein/ $\beta$-actin expression levels of Bcl-2, Bax and cleaved caspase-3 following Dex treatment and transfection with miR-375 mimic measured using western blot analysis. $\beta$-actin was employed as an internal control. All experiments were performed in triplicate and experimental data are expressed as the mean \pm standard deviation. ${ }^{* * * *} \mathrm{P}<0.001$ vs. Control; ${ }^{\wedge} \mathrm{P}<0.05,{ }^{\wedge \wedge} \mathrm{P}<0.001$ vs. Dex + MC. MC, miR-375 mimic control; M, miR-375 mimic; Dex, dexamethasone.

A

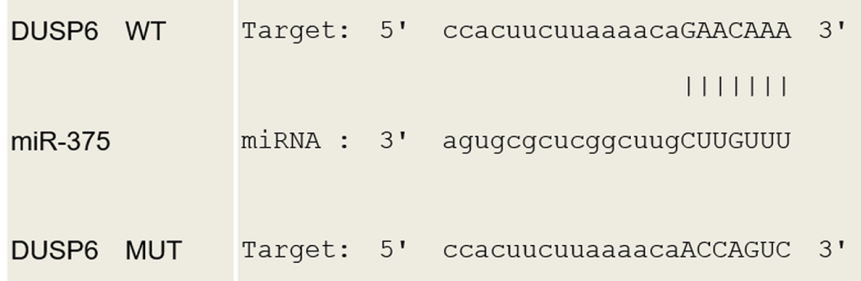

C

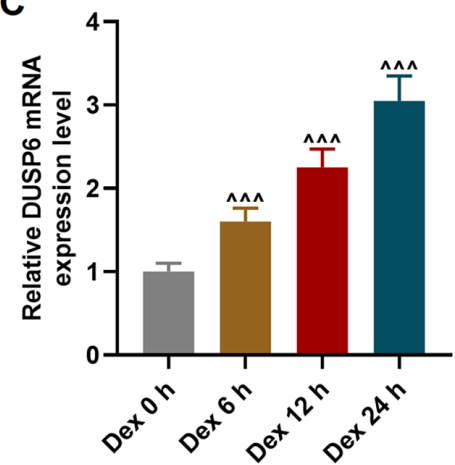

D

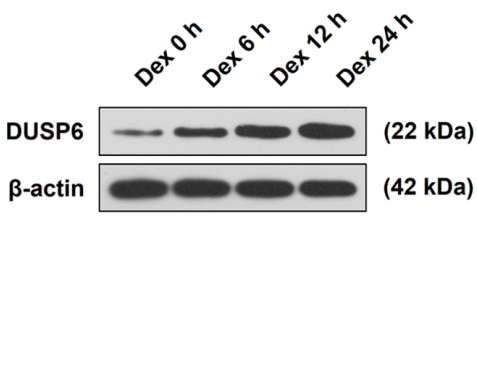

B
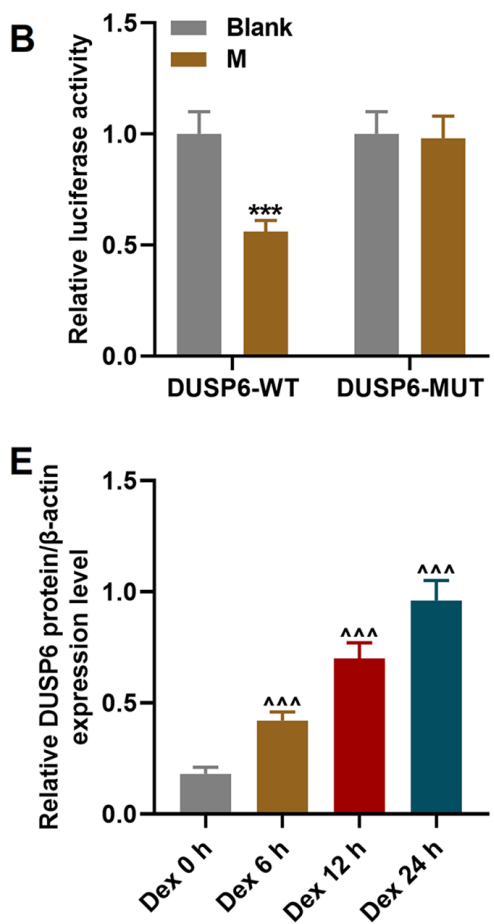

Figure 4. The expression of DUSP6, the target gene of miR-375, is upregulated in a time-dependent manner following Dex treatment. (A) Sequences of DUSP6 WT (top row), miR-375 (middle row) and DUSP6 MUT (bottom row) are listed. (B) Dual-luciferase reporter assay revealed that DUSP6 was the target gene of miR-375. (C) Relative mRNA expression of DUSP6 following Dex treatment for different periods of time $(0,6,12$ and $24 \mathrm{~h})$ measured using reverse transcription-quantitative PCR. $\beta$-actin was used as an internal control. (D and E) Relative protein/ $\beta$-actin expression of DUSP6 following Dex treatment for different periods of time $(0,6,12$ and $24 \mathrm{~h})$ measured using western blot analysis. $\beta$-actin was used as an internal control. All experiments were performed in triplicate and experimental data are expressed as the mean \pm standard deviation. ${ }^{* * *} \mathrm{P}<0.001$ vs. blank; ${ }^{\wedge \wedge} \mathrm{P}<0.001$ vs. Dex 0 h. DUSP6, dual specificity phosphatase 6; M, miR-375 mimic; Dex, dexamethasone; WT, wild-type; MUT, mutant-type.

Following Dex treatment and transfection with miR-375 mimic, the migration and invasion of the 9HTE cells were measured using wound healing assay and Transwell assay, respectively. The results of the two assays demonstrated that the cell migration and invasion rates decreased following treatment with Dex for $24 \mathrm{~h}$; these effects were reversed by the overexpression of miR-375 (P<0.05, Fig. 2D-G).

Overexpression of miR-375 reverses the effects of Dex treatment on the expression levels of apoptosis-related proteins. $\mathrm{Bcl}-2$, Bax and cleaved caspase- 3 are considered as apoptosis-related proteins (23). Thus, the present study then measured their expression levels in 9HTE cells using western blot analysis after the cells were treated with Dex and transfected with miR-375 mimic. As illustrated in Fig. 3, the expression of Bcl-2 was decreased and that of Bax and cleaved caspase-3 were increased following treatment with Dex $(\mathrm{P}<0.001$, Fig. 3A and B). However, the effects of Dex treatment on the levels of these apoptosis-related proteins were reversed by the overexpression of miR-375 (P<0.05, Fig. 3).

Expression of DUSP6, the target of miR-375, is increased in a time-dependent manner following treatment with Dex. DUSP6 was predicted and recognized as the target of miR-375 using 
A

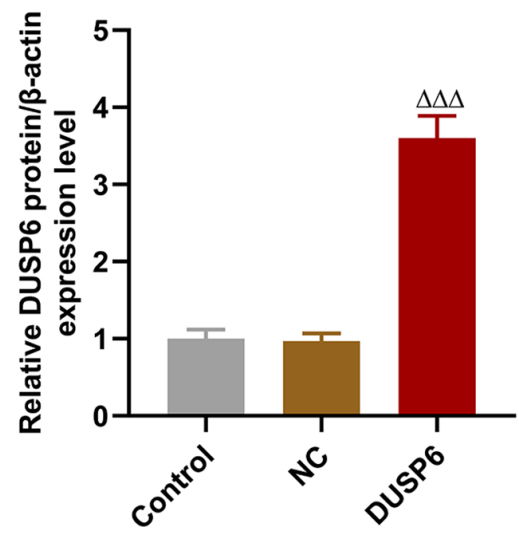

B

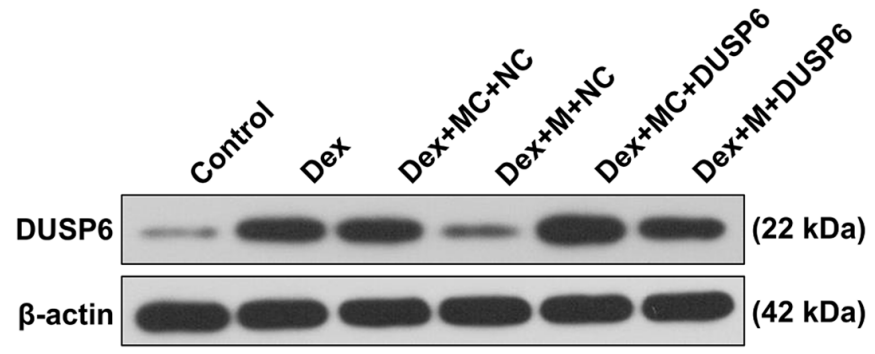

C

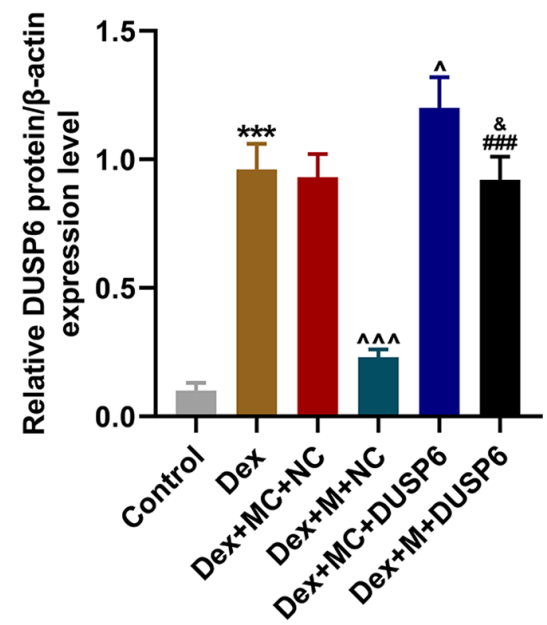

D

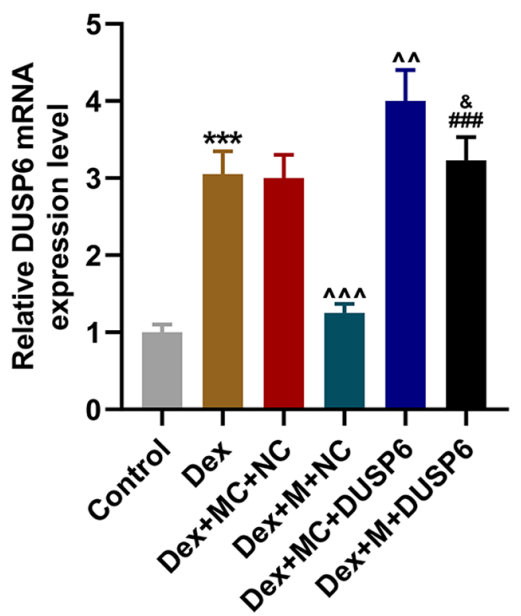

E

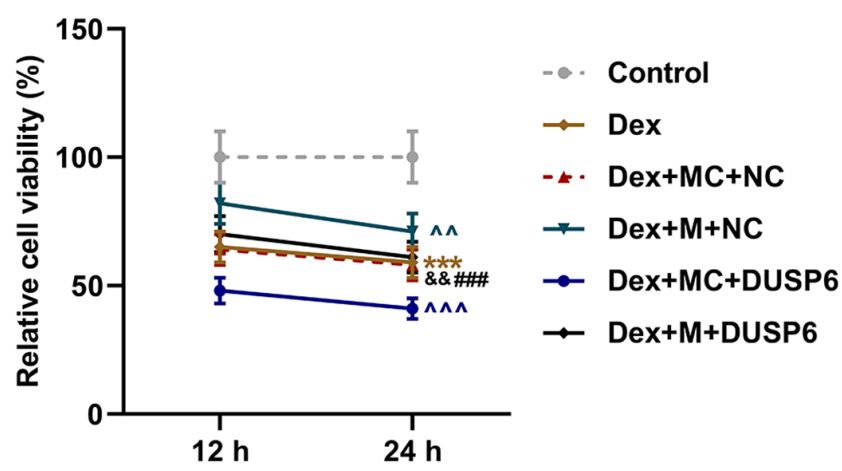

Figure 5. Overexpression of DUSP6 reverses the effects of the overexpression of miR-375 on DUSP6 expression and the viability of Dex-treated 9HTE cells. (A) Relative protein/ $\beta$-actin expression of DUSP6 following transfection with DUSP6 overexpression plasmid measured using RT-qPCR. $\beta$-actin was used as an internal control. (B and C) Relative protein/ $\beta$-actin expression of DUSP6 following Dex treatment and transfection with miR-375 mimic and DUSP6 overexpression plasmid measured using western blot analysis. $\beta$-actin was used as an internal control. (D) Relative mRNA expression of DUSP6 following Dex treatment and transfection with miR-375 mimic and DUSP6 overexpression plasmid measured using RT-qPCR. $\beta$-actin was used as an internal control (E) Relative viability of 9HTE cells following Dex treatment and transfection with miR-375 mimic and DUSP6 overexpression plasmid measured using Cell Counting Kit-8 assay. All experiments were performed in triplicate and experimental data are expressed as the mean \pm standard deviation. ${ }^{\Delta \Delta \Delta} \mathrm{P}<0.001 \mathrm{vs}$. NC; ${ }^{* * * *} \mathrm{P}<0.001$ vs. control; ${ }^{\wedge} \mathrm{P}<0.05,{ }^{\wedge} \mathrm{P}<0.01$ and ${ }^{\wedge \wedge}{ }^{\wedge} \mathrm{P}<0.001$ vs. Dex $+\mathrm{MC}+\mathrm{NC} ;{ }^{\&} \mathrm{P}<0.05$ and ${ }^{\& \&} \mathrm{P}<0.01$ vs. Dex $+\mathrm{M}+\mathrm{NC} ;{ }^{\# \# \#} \mathrm{P}<0.001$ vs. Dex $+\mathrm{MC}+\mathrm{DUSP}$. NC, negative control; DUSP6, dual specificity phosphatase 6; M, miR-375 mimic; MC, miR-375 mimic control; Dex, dexamethasone; RT-qPCR, reverse transcription-quantitative PCR.

TargetScan, and the conserved binding sites between DUSP6 and miR-375 are illustrated in Fig. 4A. To verify these results, a luciferase reporter with their $3^{\prime}$-UTRs was constructed. The results from dual-luciferase reporter assay demonstrated that the luciferase activity of the DUSP6-WT-mimic (M) group was decreased in comparison with that of the DUSP6-WT-Blank group ( $\mathrm{P}<0.001$, Fig. 4B). However, no significant difference was found in the luciferase activity of the DUSP6-MUT-M group as 
A
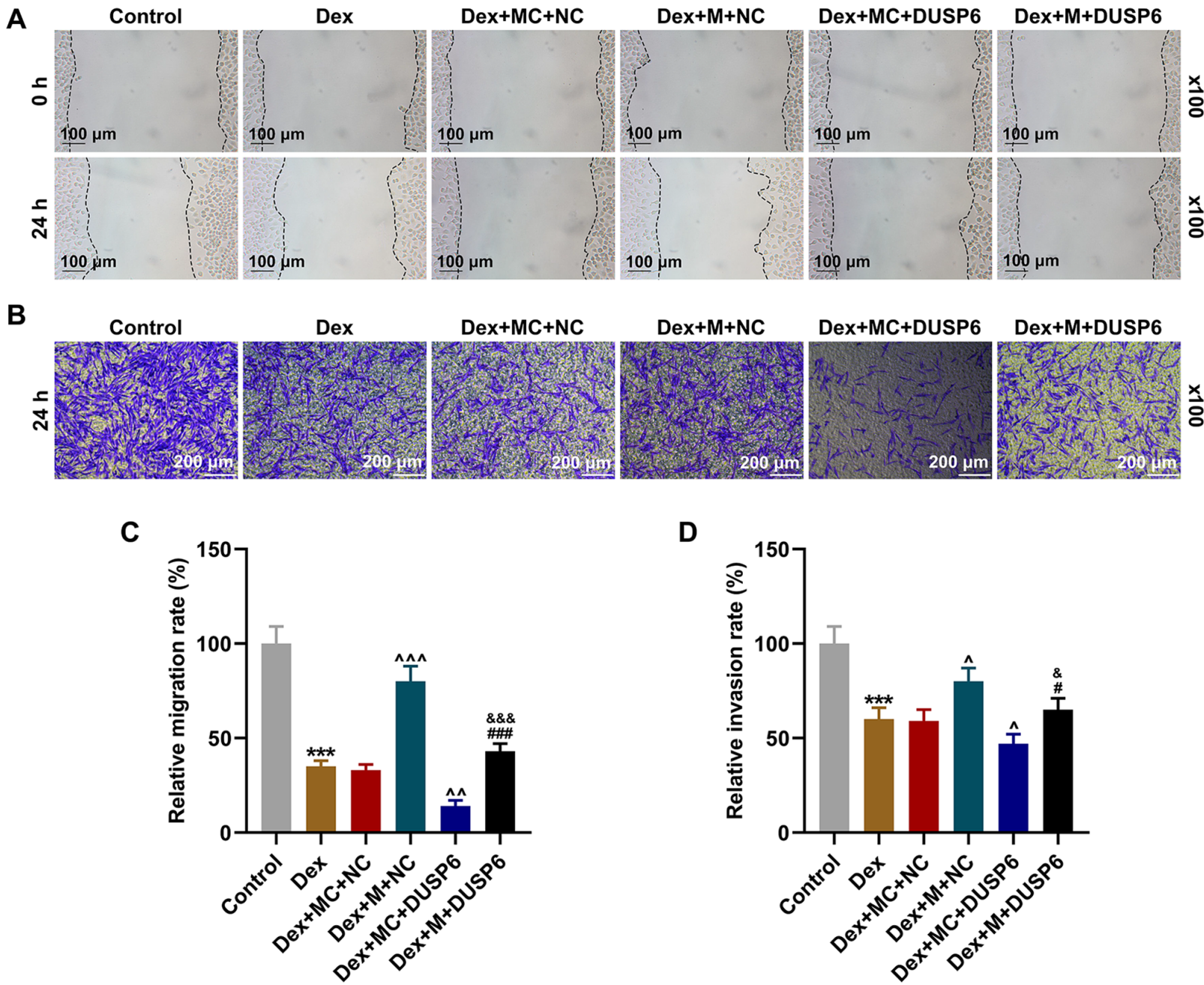

Figure 6. Overexpression of DUSP6 reversed the effects of the overexpression of miR-375 on the migration and invasion of Dex-treated 9HTE cells. (A) Relative migration of 9HTE cells following Dex treatment and transfection with miR-375 mimic and DUSP6 overexpression plasmid measured by wound healing assay at 0 and $24 \mathrm{~h}$ at x100 magnification. (B) Relative invasion rate of 9HTE cells following Dex treatment and transfection with miR-375 mimic and DUSP6 overexpression plasmid measured using Transwell assay at $24 \mathrm{~h}$ at x100 magnification. (C) Relative migration rate of $9 \mathrm{HTE}$ cells following Dex treatment and transfection with miR-375 mimic and DUSP6 overexpression plasmid. (D) Relative invasion rate of 9HTE cells following Dex treatment and transfection with miR-375 mimic and DUSP6 overexpression plasmid. All experiments were performed in triplicate and experimental data are expressed as then mean \pm standard deviation. ${ }^{* * *} \mathrm{P}<0.001$ vs. control; ${ }^{\wedge} \mathrm{P}<0.05,{ }^{\wedge \wedge} \mathrm{P}<0.001$ and ${ }^{\wedge \wedge}{ }^{\wedge} \mathrm{P}<0.001$ vs. Dex $+\mathrm{MC}+\mathrm{NC} ;{ }^{\&} \mathrm{P}<0.05$ and ${ }^{\& \& \&} \mathrm{P}<0.001$ vs. Dex $+\mathrm{M}+\mathrm{NC} ;{ }^{\# \# \#} \mathrm{P}<0.001$ vs. Dex + MC + DUSP6. NC, negative control; DUSP6, dual specificity phosphatase 6; M, miR-375 mimic; MC, miR-375 mimic control; Dex, dexamethasone.

compared to that of the DUSP6-MUT-Blank group. Therefore, it was suggested that DUSP6 was the target gene of miR-375.

To determine the role of DUSP6 in the 9HTE cells, its expression was measured following treatment with Dex for different periods of time $(0,6,12$ and $24 \mathrm{~h})$. The results revealed that the mRNA and protein expression levels of DUSP6 were increased in a time-dependent manner following Dex treatment $(\mathrm{P}<0.001$, Fig. 4C-E).

Overexpression of DUSP6 reverses the effects of the overexpression of miR-375 on the expression of DUSP6 and the viability of Dex-treated 9HTE cells. Subsequently, the 9HTE cells were transfected with DUSP6 overexpression plasmid, and it was found that DUSP6 expression was increased following transfection with DUSP6 overexpression plasmid $(\mathrm{P}<0.001$, Fig. 5A). To further examine the effects of DUSP6 and miR-375 on Dex-treated 9HTE cells, miR-375 mimic and DUSP6 overexpression plasmid were transfected into the cells followed by treatment with Dex. The results revealed that the protein and mRNA expression levels of DUSP6 in the 9HTE cells were notably increased following Dex treatment, and these effects were reversed by miR-375 overexpression $(\mathrm{P}<0.001$, Fig. 5B-D). Furthermore, the overexpression of DUSP6 abrogated the effects of miR-375 overexpression on the protein and mRNA expressions of DUSP6 ( $\mathrm{P}<0.05$, Fig. 5B-D).

The viability of the Dex-treated 9HTE cells was then detected using CCK-8 assay following transfection with miR-375 mimic and DUSP6 overexpression plasmid. The results indicated that 9HTE cell viability was decreased following Dex treatment, which was reversed by miR-375 overexpression. Moreover, the overexpression of DUSP6 reversed the effects of miR-375 overexpression on the viability of Dex-treated 9HTE cells $(\mathrm{P}<0.01$, Fig. 5E).

Overexpression of DUSP6 reverses the effects of the overexpression of miR-375 on the migration and invasion of Dex-treated 9HTE cells. The migration of Dex-treated 9HTE cells was assessed using wound healing assay following 
A

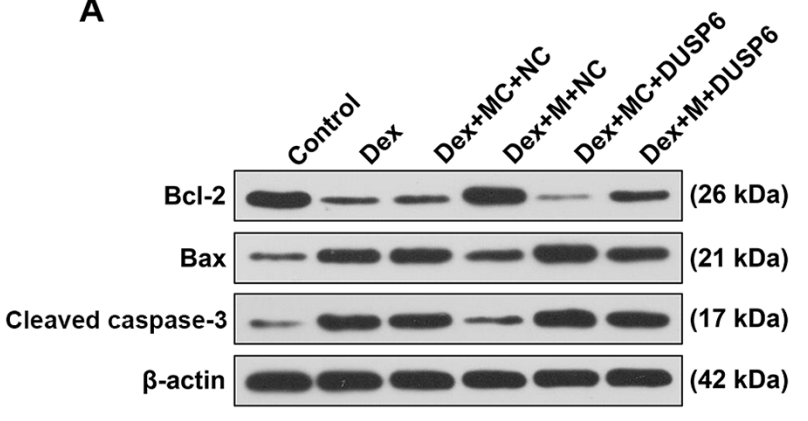

B

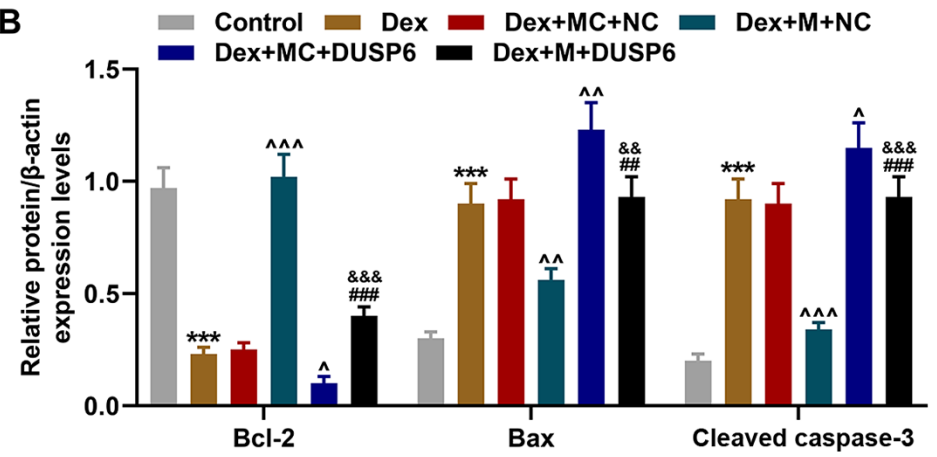

Figure 7. Overexpression of DUSP6 reversed the effects of the overexpression of miR-375 on the expression of apoptosis-related proteins in Dex-treated 9HTE cells. (A and B) Protein/ $\beta$-actin expression levels of Bcl-2, Bax and cleaved caspase-3 following Dex treatment and transfection with miR-375 mimic and DUSP6 overexpression plasmid measured using western blot analysis. $\beta$-actin was employed as an internal control. All experiments were performed in triplicate and experimental data are expressed as the mean \pm standard deviation. ${ }^{* * *} \mathrm{P}<0.001$ vs. control; ${ }^{\wedge} \mathrm{P}<0.05,{ }^{\wedge} \mathrm{P}<0.01$ and ${ }^{\wedge \wedge} \mathrm{P}<0.001$ vs. Dex $+\mathrm{MC}+\mathrm{NC}$; ${ }^{\&}{ }^{\mathrm{P}}<0.01$ and ${ }^{\& \& \&} \mathrm{P}<0.001$ vs. Dex $+\mathrm{M}+\mathrm{NC} ;{ }^{\# \#} \mathrm{P}<0.01$ and ${ }^{\# \# \#} \mathrm{P}<0.001$ vs. Dex + MC + DUSP6. NC, negative control; DUSP6, dual specificity phosphatase 6; M, miR-375 mimic; MC, miR-375 mimic control; Dex, dexamethasone.

transfection with miR-375 mimic and DUSP6 overexpression plasmid. The results revealed that the cell migration rate following Dex treatment was suppressed, and this effect was reversed by the overexpression of miR-375 $(\mathrm{P}<0.001$, Fig. 6A and C). In addition, DUSP6 overexpression reversed the effects of the overexpression of miR-375 on the migration of Dex-treated 9HTE cells ( $\mathrm{P}<0.001$, Fig. 6A and C).

The invasion of Dex-treated 9HTE cells was examined using Transwell assay following transfection of miR-375 mimic and DUSP6 overexpression plasmid. The cell invasion rate following Dex treatment was reduced, which was counteracted by the overexpression of miR-375 $(\mathrm{P}<0.05$, Fig. 6B and D). The overexpression of DUSP6 abrogated the effects of the overexpression of miR-375 on the invasion of Dex-treated 9HTE cells ( $\mathrm{P}<0.05$, Fig. 6B and D).

Overexpression of DUSP6 reverses the effects of the overexpression of miR-375 on the expression levels of cell apoptosis-related proteins in Dex-treated $9 H T E$ cells. Following transfection with miR-375 mimic and DUSP6 overexpression plasmid, the expression levels of cell apoptosis-related proteins (Bcl-2, Bax and cleaved caspase-3) in the Dex-treated 9HTE cells were measured using western blot analysis. The results confirmed that following Dex treatment, the expression of Bcl-2 was decreased, while that of Bax and cleaved caspase- 3 was increased $(\mathrm{P}<0.001$, Fig. 7). The overexpression of miR-375 led to an opposite result $(\mathrm{P}<0.01$, Fig. 7$)$. In addition, the overexpression of DUSP6 was found to reverse the effects of miR-375 on the protein expression levels of $\mathrm{Bcl}-2, \mathrm{Bax}$ and cleaved caspase-3 in the Dex-treated 9HTE cells $(\mathrm{P}<0.01$, Fig. 7).

\section{Discussion}

The human airway epithelium forms the mucosal interface between inhaled environment and the lung (24). Increasing evidence has indicated that in patients with asthma, the airway epithelium is structurally and functionally abnormal, with increased mucus production, higher permeability, enhanced oxidant sensitivity, and deficient innate immune response to viruses (25). Nowadays, ICS combined with second controller medications have been widely adopted for the management of mild or moderate asthma in adults and children (26), although the results may vary in patients.

Dex is a synthetic GC compound with anti-inflammatory, immunosuppressive and decongestant effects $(27,28)$. A number of studies have proposed that Dex exerts promising effects in the treatment of several diseases, including acute myeloid leukemia (29), macular edema (30) and noninfectious uveitis (31). Furthermore, Dex has also been found useful in preventing respiratory distress, particularly asthma $(32,33)$. The present study concentrated on human AECs, namely the 9HTE cell line. It was found that following Dex treatment, cell viability was suppressed, whereas cell apoptosis was promoted in a time-dependent manner. Further investigations also confirmed that Dex treatment led to the downregulation of miR-375, a novel potential therapeutic target for asthma treatment (34).

miRNAs have been found to affect cell proliferation, metastasis and apoptosis (35). Previous studies have suggested that miR-375 can promote the progression of inflammatory bowel disease by upregulating Toll-like receptor 4 (36). In addition, miR-375 has been shown to prevent nasal mucosa cells from apoptosis and to ameliorate allergic rhinitis by suppressing the JAK2/STAT3 pathway (37). Furthermore, miR-375 has been verified to promote cell growth in small cell lung carcinoma (38). In the present study, the overexpression of miR-375 reversed the suppressive effects of Dex treatment on AEC viability, migration and invasion. Bcl-2, Bax and cleaved caspase-3 have been found to exert effects on apoptosis, an important process where the function of normal epithelial tissue is maintained $(23,39)$. It has been reported that the upregulation of $\mathrm{Bcl}-2$ suppresses apoptosis, while the upregulation of Bax and cleaved caspase- 3 promotes apoptosis $(40,41)$. Moreover, the present study also proved that the expression of $\mathrm{Bcl}-2$ was downregulated, while that of Bax and cleaved caspase-3 was upregulated following Dex treatment; these effects were reversed by the overexpression of miR-375, indicating that the overexpression miR-375 abrogated the promoting effects of Dex on cell apoptosis. However, the detailed molecular mechanisms remain to be further addressed.

DUSP6 belongs to the mitogen-activated protein kinase (MAPK) family that can serve as a feedback regulator of 
MAPK cascades (18). Accumulating evidence has indicated that DUSP6 functions as a critical mediator in inflammatory responses. Hsu et al (42) proposed that DUSP6 promoted endothelial inflammation via intercellular adhesion molecule-1. It has also been demonstrated that DUSP6 deletion can enhance the regulation of colonic inflammatory responses and the protection of the intestinal epithelium against oncogenic stress by controlling the activation of ERK1/2 (43). In addition, chemokine (C-C motif) ligand 2-enhanced macrophage inflammation responses may be related to the suppression of ERK phosphatase DUSP6 (44). A previous study verified that DUSP6 played a tumor-suppressive role by inhibiting apoptosis (45). In the present study, it was confirmed that the expression of DUSP6, the target of miR-375, was upregulated in a time-dependent manner following Dex treatment. Furthermore, the overexpression of DUSP6 was proven to reverse the effects of the overexpression of miR-375 on AEC viability, migration and invasion, as well as the expression of apoptosis-related proteins (Bcl-2, Bax and cleaved caspase-3) in Dex-treated cells. Therefore, it could be summarized that the overexpression of miR-375 reverses the effects of Dex treatment on AEC viability, migration, invasion and apoptosis by targeting DUSP6.

However, since the in vitro exploration of the roles of Dex, miR-375 and DUSP6 in AECs was performed in the present study, the authors aim to validate these results through in vivo investigations in the future.

In conclusion, the present study demonstrated study that the overexpression of miR-375 reversed the effects of Dex treatment on human AEC viability, migration, invasion and apoptosis in vitro by targeting DUSP6. It is hoped that these findings may provide novel roles and evidence of Dex and miR-375 in AEC dysfunction, thereby providing a potential therapeutic strategy for AEC dysfunction.

\section{Acknowledgements}

Human AECs, the 9HTE cell line, were obtained from the Respiratory Research Laboratory (Key Laboratory of Child Development and Disorders of Ministry of Education, Children's Hospital, Chongqing, China). The authors are sincerely grateful to Ying Huang (chief physician), for providing the 9HTE cells for this study.

\section{Funding}

No funding was received.

\section{Availability of data and materials}

The analyzed data sets generated during the study are available from the corresponding author on reasonable request.

\section{Authors' contributions}

$\mathrm{XZ}$ made substantial contributions to the conception and design of the study. CL and XG were involved in data acquisition, data analysis and interpretation. XZ was involved in the drafting of the article or critically revising it for important intellectual content. All authors confirm the authenticity of all the raw data. All authors gave the final approval of the final version of the manuscript to be published. All authors agree to be accountable for all aspects of the work in ensuring that questions related to the accuracy or integrity of the work are appropriately investigated and resolved.

\section{Ethics approval and consent to participate}

Not applicable.

\section{Patient consent for publication}

Not applicable.

\section{Competing interests}

The authors declare that they have no competing interests.

\section{References}

1. Shine S, Muhamud S and Demelash A: Prevalence and associated factors of bronchial asthma among adult patients in Debre Berhan Referral Hospital, Ethiopia 2018: A cross-sectional study. BMC Res Notes 12: 608, 2019.

2. Ye C, Huang C, Zou M, Hu Y, Luo L, Wei Y, Wan X, Zhao H, Li W, Cai S, et al: The role of secreted Hsp90 $\alpha$ in HDM-induced asthmatic airway epithelial barrier dysfunction. BMC Pulm Med 19: 218, 2019

3. Liu J, Zhang M, Niu C, Luo Z, Dai J, Wang L, Liu E and Fu Z: Dexamethasone inhibits repair of human airway epithelial cells mediated by glucocorticoid-induced leucine zipper (GILZ). PLoS One 8: e60705, 2013.

4. Xie B, Laxman B, Hashemifar S, Stern R, Gilliam TC, Maltsev N and White SR: Chemokine expression in the early response to injury in human airway epithelial cells. PLoS One 13: e0193334, 2018.

5. Vareille M, Kieninger E, Edwards MR and Regamey N: The airway epithelium: Soldier in the fight against respiratory viruses. Clin Microbiol Rev 24: 210-229, 2011.

6. Gon Y and Hashimoto S: Role of airway epithelial barrier dysfunction in pathogenesis of asthma. Allergol Int 67: 12-17, 2018.

7. He Y, Shi J, Nguyen QT, You E, Liu H, Ren X, Wu Z, Li J, Qiu W, Khoo SK, et al: Development of highly potent glucocorticoids for steroid-resistant severe asthma. Proc Natl Acad Sci USA 116: 6932-6937, 2019

8. Adcock IM and Mumby S: Glucocorticoids. Handb Exp Pharmacol 237: 171-196, 2017.

9. Jia S, Guo P, Ge X, Wu H, Lu J and Fan X: Overexpression of indoleamine 2,3-dioxygenase contributes to the repair of human airway epithelial cells inhibited by dexamethasone via affecting the MAPK/ERK signaling pathway. Exp Ther Med 16: 282-290, 2018.

10. Svitich OA, Sobolev VV, Gankovskaya LV, Zhigalkina PV and Zverev VV: The role of regulatory RNAs (miRNAs) in asthma. Allergol Immunopathol (Madr) 46: 201-205, 2018.

11. Zhang H, Sun Y, Rong W, Fan L, Cai Y, Qu Q, Gao Y and Zhao H: miR-221 participates in the airway epithelial cells injury in asthma via targeting SIRT1. Exp Lung Res 44: 272-279, 2018.

12. Zhou H, Li J, Gao P, Wang Q and Zhang J: miR-155: A Novel Target in Allergic Asthma. Int J Mol Sci 17: 1773, 2016.

13. Zhang X, Zhao X, Sun H, Yan Y, Huang L, Gu W, Jiang W, Wang Y, Zhu C, Ji W, et al: The role of miR-29c/B7-H3 axis in children with allergic asthma. J Transl Med 16: 218, 2018.

14. Lu TX, Lim EJ, Wen T, Plassard AJ, Hogan SP, Martin LJ, Aronow BJ and Rothenberg ME: MiR-375 is downregulated in epithelial cells after IL-13 stimulation and regulates an IL-13-induced epithelial transcriptome. Mucosal Immunol 5: 388-396, 2012.

15. Ma R, Ma L, Weng W, Wang Y, Liu H, Guo R, Gao Y, Tu J, $\mathrm{Xu} \mathrm{TL}$, Cheng J, et al: DUSP6 SUMOylation protects cells from oxidative damage via direct regulation of Drp1 dephosphorylation. Sci Adv 6: eaaz0361, 2020. 
16. Cheng Y, Zhu Y, Xu J, Yang M, Chen P, Xu W, Zhao J, Geng L and Gong S: PKN2 in colon cancer cells inhibits M2 phenotype polarization of tumor-associated macrophages via regulating DUSP6-Erk1/2 pathway. Mol Cancer 17: 13, 2018.

17. Chen L, Wang Y, Luan H, Ma G, Zhang H and Chen G: DUSP6 protects murine podocytes from high glucose-induced inflammation and apoptosis. Mol Med Rep 22: 2273-2282, 2020.

18. Gu W, Yuan Y, Wang L, Yang H, Li S, Tang Z and Li Q Long non-coding RNA TUG1 promotes airway remodelling by suppressing the miR-145-5p/DUSP6 axis in cigarette smoke-induced COPD. J Cell Mol Med 23: 7200-7209, 2019.

19. Lu M, Xu X, Xi B, Dai Q, Li C, Su L, Zhou X, Tang M, Yao Y and Yang J: Molecular network-based identification of competing endogenous RNAs in thyroid carcinoma. Genes (Basel) 9: 44, 2018.

20. Livak KJ and Schmittgen TD: Analysis of relative gene expression data using real-time quantitative PCR and the 2(-Delta Delta C(T)) method. Methods 25: 402-408, 2001.

21. van den Berge $M$ and Tasena $H$ : Role of microRNAs and exosomes in asthma. Curr Opin Pulm Med 25: 87-93, 2019.

22. Zhao L, Shi X, Wang N, Liu C and Wang J: YAP1, targeted by miR-375, enhanced the pro-angiogenesis of airway smooth muscle cells in asthma via STAT3 activation. Cell Cycle 19: 1275-1284, 2020.

23. Dolka I, Król M and Sapierzyński R: Evaluation of apoptosis-associated protein (Bcl-2, Bax, cleaved caspase-3 and p53) expression in canine mammary tumors: An immunohistochemical and prognostic study. Res Vet Sci 105: 124-133, 2016.

24. Clifford RL, Patel J, MacIsaac JL, McEwen LM, Johnson SR Shaw D, Knox AJ, Hackett TL and Kobor MS: Airway epithelial cell isolation techniques affect DNA methylation profiles with consequences for analysis of asthma related perturbations to DNA methylation. Sci Rep 9: 14409, 2019.

25. Grainge C, Dennison P, Lau L, Davies D and Howarth P: Asthmatic and normal respiratory epithelial cells respond differently to mechanical apical stress. Am J Respir Crit Care Med 190: 477-480, 2014.

26. Wang L, Liu XH, Chen H, Chen ZY, Weng XD, Qiu T and Liu L: Picroside II protects rat kidney against ischemia/reperfusioninduced oxidative stress and inflammation by the TLR4/NF- $\kappa B$ pathway. Exp Ther Med 9: 1253-1258, 2015.

27. Bordag N, Klie S, Jürchott K, Vierheller J, Schiewe H, Albrecht V, Tonn JC, Schwartz C, Schichor C and Selbig J: Glucocorticoid (dexamethasone)-induced metabolome changes in healthy males suggest prediction of response and side effects. Sci Rep 5: 15954, 2015.

28. Giles AJ, Hutchinson MND, Sonnemann HM, Jung J, Fecci PE, Ratnam NM, Zhang W, Song H, Bailey R, Davis D, et al: Dexamethasone-induced immunosuppression: Mechanisms and implications for immunotherapy. J Immunother Cancer 6: 51, 2018.

29. Bertoli S, Picard M, Bérard E, Griessinger E, Larrue C, Mouchel PL, Vergez F, Tavitian S, Yon E, Ruiz J, et al: Dexamethasone in hyperleukocytic acute myeloid leukemia. Haematologica 103: 988-998, 2018.

30. Bonfiglio V, Reibaldi M, Fallico M, Russo A, Pizzo A, Fichera S, Rapisarda C, Macchi I, Avitabile T and Longo A: Widening use of dexamethasone implant for the treatment of macular edema. Drug Des Devel Ther 11: 2359-2372, 2017.

31. Pohlmann D, Vom Brocke GA, Winterhalter S, Steurer T, Thees $S$ and Pleyer U: Dexamethasone inserts in noninfectious uveitis: a single-center experience. Ophthalmology 125: 1088-1099, 2018.
32. Piastra M, Pizza A, Gaddi S, Luca E, Genovese O, Picconi E, De Luca D and Conti G: Dexmedetomidine is effective and safe during NIV in infants and young children with acute respiratory failure. BMC Pediatr 18: 282, 2018.

33. Abaya R, Jones L and Zorc JJ: Dexamethasone compared to prednisone for the treatment of children with acute asthma exacerbations. Pediatr Emerg Care 34: 53-58, 2018.

34. Ji Y, Yang X and Su H: Overexpression of microRNA-375 impedes platelet-derived growth factor-induced proliferation and migration of human fetal airway smooth muscle cells by targeting Janus kinase 2. Biomed Pharmacother 98: 69-75, 2018.

35. Ling $H$, Fabbri $M$ and Calin GA: MicroRNAs and other non-coding RNAs as targets for anticancer drug development. Nat Rev Drug Discov 12: 847-865, 2013.

36. Wu CP, Bi YJ, Liu DM and Wang LY: Hsa-miR-375 promotes the progression of inflammatory bowel disease by upregulating TLR4. Eur Rev Med Pharmacol Sci 23: 7543-7549, 2019.

37. Wang T, Chen D, Wang P, Xu Z and Li Y: miR-375 prevents nasal mucosa cells from apoptosis and ameliorates allergic rhinitis via inhibiting JAK2/STAT3 pathway. Biomed Pharmacother 103: 621-627, 2018.

38. Jin Y, Liu Y, Zhang J, Huang W, Jiang H, Hou Y, Xu C, Zhai C, Gao X, Wang S, et al: The expression of miR-375 is associated with carcinogenesis in three subtypes of lung cancer. PLoS One 10: e0144187, 2015

39. Novaleski CK, Carter BD, Sivasankar MP, Ridner SH, Dietrich MS and Rousseau B: Apoptosis and vocal fold disease: clinically relevant implications of epithelial cell death. J Speech Lang Hear Res 60: 1264-1272, 2017.

40. Hassan M, Watari H, AbuAlmaaty A, Ohba Y and Sakuragi N: Apoptosis and molecular targeting therapy in cancer. BioMed Res Int 2014: 150845, 2014.

41. Xu G, Kuang G, Jiang W, Jiang R and Jiang D: Polydatin promotes apoptosis through upregulation the ratio of $\mathrm{Bax} / \mathrm{Bcl}-2$ and inhibits proliferation by attenuating the $\beta$-catenin signaling in human osteosarcoma cells. Am J Transl Res 8: 922-931, 2016.

42. Hsu SF, Lee YB, Lee YC, Chung AL, Apaya MK, Shyur LF, Cheng CF, Ho FM and Meng TC: Dual specificity phosphatase DUSP6 promotes endothelial inflammation through inducible expression of ICAM-1. FEBS J 285: 1593-1610, 2018.

43. Beaudry K, Langlois MJ, Montagne A, Cagnol S, Carrier JC and Rivard N: Dual-specificity phosphatase 6 deletion protects the colonic epithelium against inflammation and promotes both proliferation and tumorigenesis. J Cell Physiol 234: 6731-6745, 2019.

44. Carson WF IV, Salter-Green SE, Scola MM, Joshi A, Gallagher KA and Kunkel SL: Enhancement of macrophage inflammatory responses by CCL2 is correlated with increased miR-9 expression and downregulation of the ERK1/2 phosphatase Dusp6. Cell Immunol 314: 63-72, 2017.

45. Zhang Z, Kobayashi S, Borczuk AC, Leidner RS, Laframboise T, Levine AD and Halmos B: Dual specificity phosphatase 6 (DUSP6) is an ETS-regulated negative feedback mediator of oncogenic ERK signaling in lung cancer cells. Carcinogenesis 31: $577-586,2010$

This work is licensed under a Creative Commons Attribution-NonCommercial-NoDerivatives 4.0 International (CC BY-NC-ND 4.0) License. 